\title{
Isolation of mycobacteria from patients seropositive for the human immunodeficiency virus (HIV) in south east England: 1984-92
}

\author{
M D Yates, A Pozniak, J M Grange
}

\begin{abstract}
Background-Tuberculosis and other mycobacterial infections are well recognised complications of HIV infection and surveillance is thus required.
\end{abstract}

Methods-All mycobacteria isolated from HIV positive subjects and referred to the Public Health Laboratory Service South East Regional Tuberculosis Centre (SERTC) from the first such case in 1984 until the end of 1992 were reviewed.

Results-A total of 803 mycobacteria isolated from $727 \mathrm{HIV}$ positive subjects were referred to the SERTC during the study period. A single species was isolated from 660 patients: 150 members of the tuberculosis complex (146 M tuberculosis, two $M$ bovis, and two $M$ africanum), 356 M avium-intracellulare (MAI), and 154 other environmental mycobacteria. More than one mycobacterium was isolated from 67 patients. In 12 cases $M$ tuberculosis and MAI were isolated from the same patient, almost always in that sequence, with an interval of 8-41 months between isolations. Most of the 407 isolates of MAI (74\%) were considered to be clinically significant and often caused disseminated disease. In other cases single isolates of MAI were obtained from sputum or faeces and occasionally such isolates preceded disseminated disease by several months. Only $33(14 \%)$ of the 229 isolates of environmental mycobacteria other than MAI were considered clinically significant.

Conclusions-HIV related mycobacterial disease is increasing in incidence in south east England. Further studies are required to determine the significance of single isolates of MAI and other environmental mycobacteria as a guide to the need for preventive chemotherapy or immunotherapy.

(Thorax 1993;48:990-995)

It is well established that the human immunodeficiency virus (HIV) predisposes the infected subject to mycobacterial disease. ${ }^{1}$ Tuberculosis is usually the result of reactivation of dormant disease and tends to develop in the HIV positive subject before the AIDS defining diseases. ${ }^{2}$ Disease due to the envi- $\vec{O}$ ronmental ("atypical") mycobacteria, by con- $\overrightarrow{\vec{\omega}}$ trast, tends to occur much later in the course of the HIV infection and usually after an AIDS defining diagnosis has already been made.

For reasons that are not understood, $\vec{\circ}$ Mycobacterium avium -is the most frequent environmental species to cause such AIDS related disease. This species is usually grouped together with the very closely related species $M$ intracellulare to form the $M$ aviumintracellulare (MAI) complex, although most strains isolated from patients with AIDS conform to the species $M$ avium. ${ }^{3}$ The impact of $\vec{c}$ opportunist disease due to $M$ avium on AIDS varies from region to region. In the USA about $50 \%$ of patients with AIDS ultimately develop this disease, ${ }^{4}$ while in Sweden the incidence is about $10 \% .^{5}$

Although able to cause overt disease in $\triangle$ HIV positive subjects, environmental $\overrightarrow{\overrightarrow{0}}$ mycobacteria may occur as transient sapro- 3 phytes in the respiratory tract and the intestines and often contaminate the lower? urethra and external genitalia. Thus, as in HIV negative subjects, the isolation of environmental mycobacteria from sputum, faeces or urine must be interpreted with caution. On the other hand, it is important to establish whether apparently casual isolates may proceed to disseminated disease and therefore point to the need for preventive antibacterial therapy.

The aim of this study is to document the types of mycobacteria isolated from patients $\sigma$ known to be HIV positive and referred to the $N$ PHLS South East Regional Tuberculosis $\underset{\mathrm{N}}{\mathrm{N}}$ Centre, Dulwich, from the time that such 0 patients were first seen (1984) until the endo of 1992. This regional centre receives $\mathbb{\mathscr { D }}$ mycobacteria isolated by about 90 client lab- $\stackrel{?}{?}$ oratories in London and south east England, $\underset{T}{T}$ amounting to about $95 \%$ of all isolates in the $\frac{\vec{D}}{\mathbb{D}}$ region. ${ }^{6}$ It serves as a reference laboratory to several HIV units in south east England, $\stackrel{\triangleright}{\circ}$ including all but one of the major units in London.

\section{Methods}

Information on the age, sex, and HIV status of the patients and the site of isolation of the organisms was supplied by the client labora- 
tories. In the case of disease due to mycobacteria other than tubercle bacilli, a further check was made by asking the referring laboratory if the HIV status was known. This was, however, not practical in the case of tuberculosis in view of the large number of strains received. The ethnic origins of the patients were determined by their names, with the assistance of laboratory staff from various ethnic groups. This is not an ideal method ${ }^{7}$ because patients of Afro-Caribbean origin are included in the European group.

Mycobacteria were identified by routine cultural and biochemical tests ${ }^{8}$ with, in some cases, use of DNA probes to confirm the identity of strains in the Mycobacterium avium-intracellulare complex. Strains identified as members of the tuberculosis complex were divided into the constituent species $M$ tuberculosis, $M$ bovis, and $M$ africanum. ${ }^{9}$ Strains in this group were tested for susceptibility to isoniazid, streptomycin, rifampicin, pyrazinamide, and ethambutol. The incidence of drug resistance was compared with overall figures for south east England for 1984-91.10

The putative clinical significance of mycobacteria other than those of the tuberculosis complex was assessed from the site and frequency of isolation. Strains considered to be of doubtful clinical significance included single isolates, or more than one isolate within a period of one month from the same or different non-sterile sites (sputum, bronchial washings, stool, or urine). Strains considered to be of probable clinical significance included those isolated from blood, bone marrow, bone, lymph nodes, other tissue lesions, and multiple isolations including at least one from a site that is usually sterile. Pulmonary isolates were considered significant if two or more isolates were obtained over a period exceeding one month or if there was evidence of extrapulmonary spread of disease.

Data were analysed statistically by the
Student's $t$ test and Fisher's exact test as indicated in the text.

\section{Results}

A total of 803 mycobacteria from 727 subjects infected with HIV were received during the study period 1984-92. The annual isolation rate of mycobacteria is shown in table 1 . In 660 cases a single species was isolated: 150 members of the tuberculosis complex (146 $M$ tuberculosis, two $M$ bovis, and two $M$ africanum), $356 \mathrm{M}$ avium-intracellulare (MAI), and 154 other species of environmental mycobacteria. More than one mycobacterium was isolated from 67 patients: $12 \mathrm{M}$ tuberculosis with MAI, five $M$ tuberculosis with other environmental mycobacteria, $39 \mathrm{MAI}$ with other environmental mycobacteria, and 11 cases of two or more other environmental mycobacteria. Members of the tuberculosis complex were thus isolated from 167 patients (23\%) and MAI from 407 patients (56\%). A total of 229 environmental mycobacteria other than MAI were isolated from 209 patients $(29 \%)$.

Table 2 shows the sex and ethnic origins of the patients. Most were men of European ethnic origin. The proportion of women in the African group was significantly higher than in the European group (34\% $v 4.2 \%$, $\mathrm{p}<0.00001$, Fisher's exact test).

The mean (SD) age of the European patients was $37 \cdot 3(8 \cdot 8)$ years (range 9-86), for patients from the Indian subcontinent it was $35.2(7.9)$ years (range 27-55), and for the African patients it was $32.0(7 \cdot 1)$ years (range 19-48). The age difference between the European and African patients was significant $(\mathrm{t}=3 \cdot 84, \mathrm{p}<0.001)$.

Figure 1 shows the annual isolation rate of members of the tuberculosis complex from 167 patients and table 3 shows the sites of isolation: 81 isolations (49\%) were from single or multiple non-pulmonary sites. Members of the tuberculosis complex were

Table 1 Annual numbers of members of the tuberculosis complex, $M$ avium-intracellulare (MAI) and other environmental mycobacteria isolated from HIV positive patients and the total number of strains received

\begin{tabular}{|c|c|c|c|c|c|c|c|c|c|c|}
\hline Species & 1984 & 1985 & 1986 & 1987 & 1988 & 1989 & 1990 & 1991 & 1992 & Total \\
\hline \multicolumn{11}{|l|}{ Strains from known HIV positive patients: } \\
\hline Tuberculosis complex & 2 & 4 & 7 & 16 & 17 & 24 & 26 & 29 & 42 & 167 \\
\hline MAI & 1 & 1 & 18 & 13 & 27 & 48 & 61 & 77 & 161 & 407 \\
\hline$M$ kansasii & - & - & 5 & 4 & 2 & 4 & 7 & 9 & 11 & 42 \\
\hline M xenopi & 2 & - & 1 & 2 & 9 & 4 & 15 & 20 & 16 & 69 \\
\hline$M$ chelonae & - & - & - & 2 & 4 & - & 3 & 10 & 3 & 22 \\
\hline$M$ fortuitum & - & - & - & - & 1 & 1 & 5 & 8 & 7 & 22 \\
\hline$M$ gordonae & - & - & - & - & 1 & 1 & 7 & 12 & 24 & 45 \\
\hline$M$ malmoense & - & - & 1 & - & - & - & - & 6 & 1 & 8 \\
\hline$M$ flavescens & - & - & - & 1 & 2 & - & 4 & 4 & 3 & 14 \\
\hline$M$ scrofulaceum & - & - & - & - & 2 & - & 1 & - & - & 3 \\
\hline$M$ szulgai & - & - & - & - & - & - & 1 & - & - & 1 \\
\hline$M$ haemophilum & - & - & - & - & - & - & 1 & - & - & 1 \\
\hline$M$ simiae & - & - & - & 一 & - & - & - & - & 1 & 1 \\
\hline Unidentified & - & - & - & - & - & - & - & 1 & - & 1 \\
\hline Total other environmental mycobacteria & 2 & - & 7 & 9 & 21 & 10 & 44 & 70 & 66 & 229 \\
\hline \multicolumn{11}{|l|}{ Total number of strains received: } \\
\hline Tuberculosis complex & 1183 & 1236 & 1206 & 1148 & 1028 & 1088 & 1178 & 1252 & 1263 & \\
\hline MAI & 36 & 46 & 61 & 43 & 65 & 89 & 123 & 142 & 250 & 855 \\
\hline Other environmental mycobacteria & 357 & 333 & 255 & 272 & 291 & 283 & 297 & 350 & 371 & 2809 \\
\hline
\end{tabular}


Table 2 Sex and ethnic origin of HIV positive patients from whom mycobacteria were isolated

\begin{tabular}{|c|c|c|c|c|c|c|c|}
\hline \multirow[b]{2}{*}{ Sex } & \multicolumn{7}{|c|}{ Ethnic origin } \\
\hline & European & African & $\begin{array}{l}\text { Indian } \\
\text { Subcontinent }\end{array}$ & Far East & Other & Unknown & Total \\
\hline Male & 608 & 35 & 13 & 7 & 3 & 9 & 675 \\
\hline Female & 27 & 18 & - & 2 & 1 & 1 & 49 \\
\hline Unknown & 2 & - & - & - & - & 1 & 3 \\
\hline Total & 637 & 53 & 13 & 9 & 4 & 11 & 727 \\
\hline
\end{tabular}

Figure 1 Annual numbers of members of the tuberculosis complex ( $M$ tuberculosis, $M$ bovis, and $M$ africanum) isolated from HIV positive subjects.

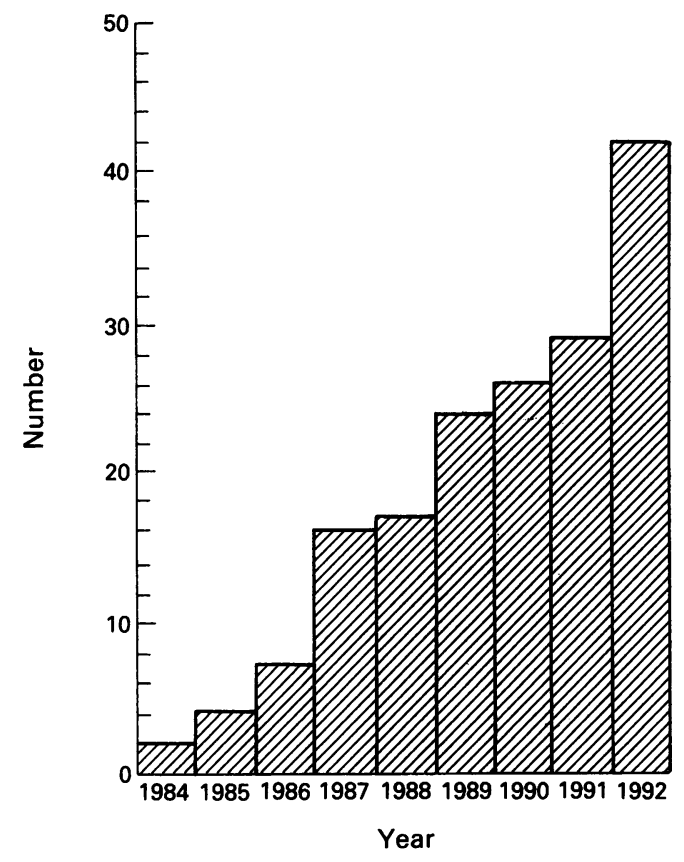

isolated from $38(72 \%)$ of the 53 patients of African ethnic origin, and from 124 (20\%) of the 637 patients of European ethnic origin. The respective numbers from whom MAI were isolated were $14(26 \%)$ and $374(59 \%)$. The difference in frequency of isolation of members of the tuberculosis complex and MAI in both of these ethnic groups was highly significant $(p<0.001$, Fisher's exact test).

Nine (5\%) of the 167 isolates of $M$ tuberculosis were resistant to one or more of the tested drugs. These strains were isolated from six (16\%) of the 38 patients of African ethnic origin (three strains resistant to isoniazid, one to streptomycin, and one to both isoniazid and streptomycin) and from three (2\%) of the 124 patients of European ethnic origin (two strains resistant to isoniazid and one to rifampicin). These percentages did not differ significantly from the overall percentages of drug resistance in the two ethnic groups ( $11 \%$ and $2.9 \%$ respectively, Fisher's exact test).

In 12 cases (nine European and three African) MAI was isolated from patients from whom $M$ tuberculosis was also isolated. In 11 cases MAI was isolated after $M$ tuberculosis with a mean interval of 21 months (range $7-41$ ). In one case there was a single isolate of MAI from stool one month before isolation of $M$ tuberculosis from sputum. Eight of these 12 MAI infections were disseminated and four were of doubtful clinical significance (isolates from sputum, stool and bile). In five cases (three European and two African) other environmental mycobacteria were isolated from patients from whom $M$ tuberculosis was isolated. The environmental mycobacteria were isolated before, after, or simultaneously to $M$ tuberculosis. All were single isolates from the lung, stool or urine and were of doubtful clinical significance.

Table 4 shows the site(s) from which MAI was isolated. In most cases ( $74 \%$ ) the site indicated that the patient had disseminated or other forms of clinically significant disease. In $15(5 \%)$ of the 300 cases that were probably clinically significant MAI had been isolated from sputum or bronchoalveolar lavage fluid (four cases), stool (eight cases), or both lung and stool (three cases) more than three months previously (mean 8.5 months, range 3-23). The annual numbers of MAI of probable and doubtful significance are shown in fig 2.

Table 5 shows patients from whom environmental mycobacteria of probable and of doubtful clinical significance were isolated. In four cases of probable disease (due to $M$ fortuitum, $M$ xenopi, and two $M$ malmoense) the patient also had disease due to MAI: simul-

Table 3 Type of disease, according to site of isolation, caused by the tuberculosis complex in HFV positive patients

\begin{tabular}{|c|c|c|c|c|c|c|c|c|c|c|}
\hline & 1984 & 1985 & 1986 & 1987 & 1988 & 1989 & 1990 & 1991 & 1992 & Total \\
\hline \multicolumn{11}{|l|}{$M$ tuberculosis } \\
\hline Pulmonary & - & 2 & 4 & 9 & 9 & 11 & 16 & 14 & 20 & 85 \\
\hline Disseminated ${ }^{\star}$ & - & - & - & 3 & 1 & 6 & 3 & 6 & 6 & 25 \\
\hline Lymphadenitis & 1 & 2 & 2 & 4 & 5 & 2 & 2 & 6 & 10 & 34 \\
\hline Central nervous system & 1 & - & - & - & 一 & 1 & 2 & - & 1 & 5 \\
\hline Genitourinary & - & - & - & - & - & 2 & - & 2 & 3 & 7 \\
\hline Pericardium & - & - & - & - & - & 1 & - & - & - & 1 \\
\hline Stool & - & - & 1 & - & - & 1 & 1 & - & - & 3 \\
\hline Abdomen & - & - & - & - & 1 & - & - & - & 1 & 2 \\
\hline Skin & - & - & - & - & - & - & - & - & 1 & 1 \\
\hline \multicolumn{11}{|l|}{$M$ bovis } \\
\hline Pulmonary & - & - & - & - & - & - & 1 & - & - & 1 \\
\hline Lymphadenitis & 一 & - & - & - & - & - & - & 1 & - & 1 \\
\hline \multicolumn{11}{|l|}{$M$ africanum } \\
\hline Disseminated & - & - & - & - & 1 & - & 1 & - & - & 2 \\
\hline Total & 2 & 4 & 7 & 16 & 17 & 24 & 26 & 29 & 42 & 167 \\
\hline
\end{tabular}

^Isolations from blood, bone marrow, or multiple sites. 
Table 4 Source of isolation of $M$ avium-intracellulare (MAI) and putative clinical significance of the isolations

\begin{tabular}{|c|c|c|c|c|}
\hline \multirow[b]{2}{*}{ Site } & \multicolumn{4}{|c|}{ Number of isolates } \\
\hline & $M A I$ only & $M A I+T B C$ & $M A I+E M$ & Total \\
\hline \multicolumn{5}{|c|}{ Doubtful clinical significance: } \\
\hline Sputum only & 59 & 1 & 8 & 68 \\
\hline Stool only & 24 & 1 & 2 & 27 \\
\hline Sputum + stool & 10 & - & 1 & 11 \\
\hline Urine + stool & 1 & - & - & 1 \\
\hline Total & 94 & 2 & 11 & $107(26 \%)$ \\
\hline \multicolumn{5}{|c|}{ Probable clinical significance: } \\
\hline Pulmonary & 6 & 1 & 1 & 8 \\
\hline Lymph node only & 8 & - & - & 8 \\
\hline Blood only & 134 & 5 & 16 & 155 \\
\hline Blood + stool & 39 & 2 & 3 & 44 \\
\hline Bone marrow only & 14 & - & 2 & 16 \\
\hline Bone marrow + blood & 10 & - & 1 & 11 \\
\hline Bone marrow + stool & 5 & - & - & 5 \\
\hline Multiple sites & 41 & 1 & 5 & 47 \\
\hline Other ${ }^{\star}$ & 5 & 1 & - & 6 \\
\hline Total & 262 & 10 & 28 & $300(74 \%)$ \\
\hline
\end{tabular}

TBC— tuberculosis complex; EM-environmental mycobacteria. ${ }^{\star}$ Caecal mass, thumb, bronchial biopsy, liver only (two cases), bile.

Figure 2 Annual numbers of $M$ aviumintracellulare (MAI) of doubtful ( $\square$ ) and probable (四) clinical significance isolated from HIV positive subjects.

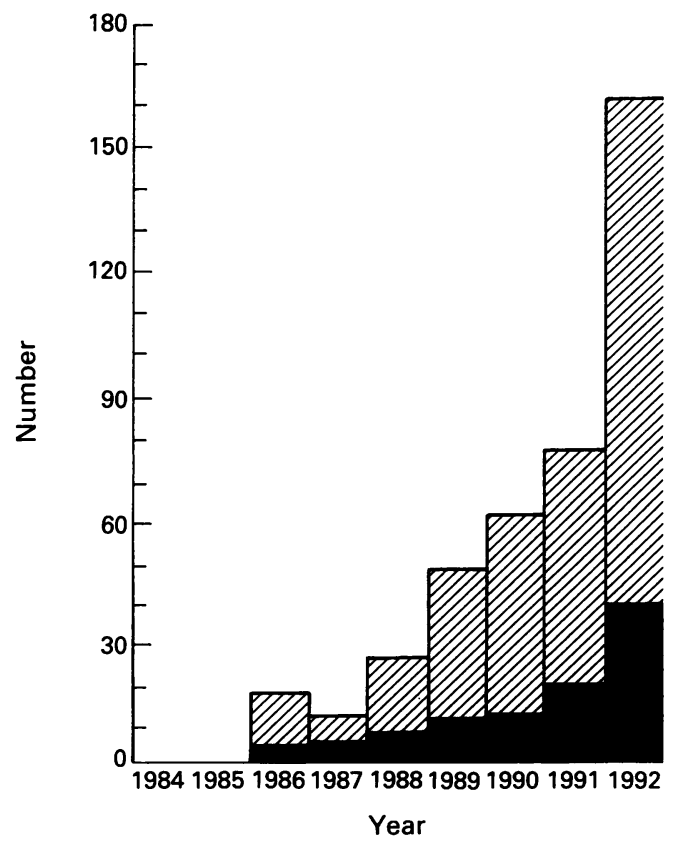

taneously in two cases and three and four months later respectively in the other two cases. The tendency to cause disease varied from species to species. The scotochromogens, $M$ gordonae and $M$ flavescens, did not cause disease; $M$ kansasii was the commonest cause of disease, mostly disseminated, while $M$ xenopi, the next commonest, tended to be associated with pulmonary disease.

The 196 environmental mycobacteria of doubtful clinical significance were isolated from sputum or bronchial washings (101 isolations), stool (32 isolations), sputum and stool (four isolations), and urine (six isolations).

A smaller proportion (33 of $229,14 \%$ ) of environmental mycobacteria other than MAI were probable causes of disease in comparison with MAI (300 of 407, 74\%, p < 0.001, Fisher's exact test). Of the total of 333 mycobacteria other than tubercle bacilli that were probable causes of disease, 300 (90\%) were MAI.

\section{Discussion}

It is possible that the HIV status of patients with mycobacterial disease was not always determined or declared by the client laboratory. By 30 June 1991, 4360 patients with AIDS in all of England and Wales had been reported to the Communicable Disease Surveillance Centre (CDSC) and 200 (4.6\%) of these were also reported to have tuberculosis. ${ }^{11}$ By 31 December 1991 we had received tubercle bacilli from 125 known HIV positive patients (table 1) which is comparable with the notification figures as about $75 \%$ of all cases of AIDS in England and Wales notified to the CDSC occur in south east England. ${ }^{12}$ In 1988 nine of $2163(0.4 \%)$ notified patients with tuberculosis in England and Wales were known to be infected with HIV. ${ }^{11}$ In the same year 17 of our 1028 patients with tuberculosis ( $1.6 \%$, table 1) were likewise known to be infected: a significantly higher proportion. The information conveyed to us therefore

Table 5 Source of isolations of environmental mycobacteria other than $M$ avium-intracellulare and putative clinical significance of the isolations

\begin{tabular}{|c|c|c|c|c|c|c|c|}
\hline \multirow[b]{2}{*}{ Species } & \multicolumn{6}{|c|}{ Probable clinical significance } & \multirow[b]{2}{*}{$\begin{array}{l}\text { Doubtful } \\
\text { clinical } \\
\text { significance }\end{array}$} \\
\hline & $\begin{array}{l}\text { Multi- } \\
\text { site }\end{array}$ & $\begin{array}{l}\text { Blood } \\
\text { and/or } \\
\text { bone } \\
\text { marrow }\end{array}$ & Lung & $\begin{array}{l}\text { Lymph } \\
\text { node }\end{array}$ & Other & Total & \\
\hline$M$ kansasii & 2 & 6 & - & - & $4^{\star}$ & 12 & 30 \\
\hline$M$ xenopi & - & 2 & 6 & 1 & - & 9 & 60 \\
\hline$M$ chelonae & - & - & - & - & 一 & - & 22 \\
\hline$M$ fortuitum & - & 3 & 1 & 1 & - & 5 & 17 \\
\hline$M$ gordonae & - & - & - & - & - & - & 45 \\
\hline$M$ malmoense & 1 & 1 & 2 & - & - & 4 & 4 \\
\hline$M$ flavescens & 一 & - & - & - & - & - & 14 \\
\hline$M$ scrofulaceum & - & 1 & - & - & - & 1 & 2 \\
\hline$M$ szulgai & - & - & 1 & - & - & 1 & 一 \\
\hline$M$ haemophilum & - & - & - & - & $1 \star \star$ & 1 & - \\
\hline$M$ simiae & - & - & - & - & - & - & 1 \\
\hline Unidentified & - & 一 & - & - & - & - & 1 \\
\hline Total & 3 & 13 & 10 & 2 & 5 & 33 & 196 \\
\hline No. of patients & 3 & 13 & 10 & 2 & 5 & 33 & 176 \\
\hline
\end{tabular}

^Elbow, tibia, finger, "abscess"; $\star \star$ foot. 
appears to be as inclusive and representative as that obtained by the notification system.

Most patients of European ethnic origin were men, reflecting pattern I spread of HIV in Europe. There were relatively more women in the African ethnic group, reflecting migratory patterns from pattern II endemic areas of HIV infection. Members of the tuberculosis complex were isolated relatively more frequently from the ethnic African patients, almost certainly because a greater proportion of this group had previously been infected by tubercle bacilli. By contrast, MAI was isolated less frequently from ethnic African patients and it has been found that HIV related opportunist MAI disease, for unknown reasons, is relatively uncommon in Africa. ${ }^{13}$

During this study period a total of 10582 cases of bacteriologically proven tuberculosis due to $M$ tuberculosis were registered at the South East Regional Tuberculosis Centre (SERTC) (table 1). The $167 \mathrm{HIV}$ related cases of tuberculosis due to this species therefore make up only a small proportion of the total $(1 \cdot 6 \%)$. The real incidence could, however, be higher as testing for antibody to HIV is not undertaken in all cases of tuberculosis. Nevertheless, the impact of HIV on the overall tuberculosis situation in Great Britain appears, at present, to be limited. ${ }^{14}$

The two cases of HIV related pulmonary tuberculosis due to $M$ bovis give cause for concern. This species is usually regarded as being less virulent for man than $M$ tuberculosis and less likely to lead to open or infectious post primary disease. Thus evidence for person-to-person transmission of $M$ bovis is limited and anecdotal. Infection by HIV could, however, abrogate any immunological factors that limit the development of open tuberculosis and could thus facilitate transmission of this bacillus within the human population, and thence to animals. ${ }^{15}$ Two of 123 cases of HIV related tuberculosis in France were caused by $M$ bovis. ${ }^{16}$

Extrapulmonary manifestations of tuberculosis, including disseminated disease, are more likely to occur in HIV infected persons than in HIV negative subjects. ${ }^{12}$ In this study $47 \%$ of patients of European ethnic origin had such manifestations, with or without pulmonary disease, compared with $19 \%$ of all patients registered at the SERTC during the same study period. ${ }^{10}$

Drug resistance was detected in some strains of $M$ tuberculosis but the incidence was not significantly different from that in the overall population. In another study conducted in London, 14 strains of $M$ tuberculosis isolated from HIV positive patients were susceptible to drugs and one was resistant to rifampicin and ethambutol. ${ }^{17}$ The serious problem of multidrug resistance that has occurred, for example, in New York and Florida ${ }^{18} 19$ has therefore not yet been encountered in London and south east England. This, however, does not exclude the need for careful continuing surveillance.

In patients from whom both tubercle bacilli and MAI were isolated, the latter was almost always isolated after the former. This agrees with the finding in the USA that tuberculosis is an early manifestation of HIV infection whereas MAI disease occurs as a late event. ${ }^{1}$ By contrast, there was no temporal $\bar{z}$ relationship between isolation of tubercle 을 bacilli and environmental species other than $\tilde{x}$ MAI. The latter isolations were of doubtful $\vec{\Rightarrow}$ clinical significance and were probably coinci- $\stackrel{\oplus}{+}$ dental contaminants.

In $5 \%$ of cases of disseminated MAI dis- $\frac{\bar{\sigma}}{\bar{c}}$ ease a member of this group had been iso- $\bar{\Phi}$ lated from sputum or stool several months before the detection of disseminated infection. As MAI is common in the environment, $\overrightarrow{0}$ the significance of its isolation from sputum $\overrightarrow{-}$ and stool is uncertain. While some workers $\omega_{\sigma}$ consider that HIV related MAI disease fol- $\stackrel{2}{\rightleftharpoons}$ lows recent infection via the lung or intestine, others suggest that it arises from longstanding 9 dormant infection of lymphatic tissue. ${ }^{20}$ It is $\overrightarrow{0}$ important to determine the significance of $₫$ early isolates as this has implications for the deployment of preventive chemotherapy or immunotherapy.

The clinical significance of environmental mycobacteria other than MAI is also difficult $\frac{0}{0}$ to determine unless they are clearly impli- $\stackrel{\Phi}{-}$ cated in non-pulmonary and disseminated $\vec{\oplus}$ disease. These mycobacteria are common in $\omega$ the environment and may easily gain access $\square$ to the respiratory and alimentary tracts and may contaminate the external genitalia and $\overline{0}$ urine of healthy persons. In HIV negative $\stackrel{2}{\circ}$ subjects a diagnosis of pulmonary or genito- $\stackrel{\mathbb{Q}}{\propto}$ urinary disease resulting from environmental $\overrightarrow{\vec{\sigma}}$ mycobacteria must be made with caution. ${ }^{21} 22 \frac{9}{3}$ The large number of isolations in this study may well reflect the intensity of bacteriologi-? cal examinations. Although stringent diagnostic criteria are required in the case of HIV positive subjects, 33 patients had definite or very probable overt disease to other environmental mycobacteria. Likewise, in the USA several species have caused disseminated disease $^{1}$ and some cases of pulmonary disease due to $M$ kansasii in patients with advanced HIV infection have been successfully $\frac{D}{0}$ treated. ${ }^{23}$

As the total population of HIV positive $N$ subjects in south east England is unknown, N the incidence of mycobacterial disease in this population cannot be assessed. A London 0 based study of $270 \mathrm{HIV}$ positive subjects ${ }_{0}$

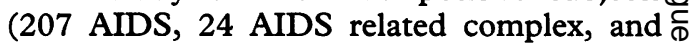
39 asymptomatic) revealed that $32(12 \%) \stackrel{?}{+}$ had mycobacterial disease: $15 \mathrm{M}$ tuberculosis, $\underline{T}$ $15 \mathrm{MAI}$, one $M$ kansasii and one $M$ ulcerans. ${ }^{17}$ Subclinical intestinal carriage of MAI and $\stackrel{\oplus}{\oplus}$ other environmental mycobacteria was com- $\stackrel{\varnothing}{\circ}$ monly encountered. In a study in France 123 으 (2\%) of $5730 \mathrm{HIV}$ positive subjects had tuberculosis (121 $M$ tuberculosis and two $M$ bovis) and other mycobacteria were isolated from $105(2 \%)$ persons (63 MAI, $16 \fallingdotseq$ $M$ xenopi, and 26 other environmental mycobacteria) but the sites of isolation and clinical significance of the latter were not recorded. ${ }^{16}$ The lower proportion of patients 
with mycobacterial disease in the French study is probably explained by a lesser overall degree of immunosuppression than in the London study. In contrast to our findings, no patient in the French study was infected by more than one mycobacterium.

In conclusion, mycobacteria are an important cause of HIV related disease but isolation of species other than MAI and members of the tuberculosis complex may not be clinically significant. Continued close bacteriological surveillance is required to determine the impact of HIV on tuberculosis in the community and to clarify the management of patients from whom other species are isolated.

We are most grateful to Dr Anne Uttley for her support and advice and Dr PA Jenkins and his staff of the Mycobacterium Reference Unit, Cardiff for confirmation of the identity of some of the species and for confirmation of drug resistance.

1 Pitchenik AE, Fertel D. Medical management of AIDS patients: tuberculosis and nontuberculous mycobacterial disease. Med Clin North Am 1992;76:121-71.

2 Festenstein F, Grange JM. Tuberculosis and the acquired immune deficiency syndrome. I Appl Bacteriol 1991; 71:19-30.

3 Grange JM, Yates MD, Boughton E. The avian tubercle bacillus and its relatives. $\mathcal{F}$ Appl Bacteriol 1990; 68:411-31.

4 Kiehn TE, Edwards FF, Brennon P, Tsang AY, Maio M, Gold JW, et al. Infections caused by Mycobacterium avium complex in immunocompromised patients: diagnosis by blood culture and fecal examination, antimicrobial susceptibility tests, and morphological and seroagglutination characteristics. $\mathcal{f}$ Clin Microbiol 1985; 21:168-73.

5 Kallenius G, Hoffner SE, Svenson SB. Does vaccination with bacille Calmette Guerin protect against AIDS? Rev Infect Dis 1989;11:349-51.

6 Watson JM, Meredith SK, Whitmore-Overton E, Bannister B, Darbyshire JH. Tuberculosis and HIV; estimates of the overlap in England and Wales. Thorax 1993;48:199-203.

7 Silito K. Ethnic origin: the search for a question. Population Trends 1978;13:25-30.

8 Collins $\mathrm{CH}$, Grange JM, Yates MD. Organization and practice in tuberculosis bacteriology. London: Butterworths, 1985.

9 Collins $\mathrm{CH}$, Yates MD, Grange JM. Subdivision of Mycobacterium tuberculosis into five variants for epidemiological purposes: methods and nomenclature. $\mathcal{f} \mathrm{Hyg}$ 1982;89:235-42.

10 Yates MD, Grange JM. A bacteriological survey of tuberculosis due to the human tubercle bacillus (Mycobacterium tuberculosis) in south-east England: 1984-1991. Epidemiol Infect 1993;110:609-19.

11 Medical Research Council Cardiothoracic Epidemiology Group. National survey of notifications of tuberculosis in England and Wales in 1988. Thorax 1992;47:770-5.

12 Communicable Disease Surveillance Centre. Communicable Disease Report 1991;45:205-6.

13 Colebunders $R$, Nembunzu M, Portaels F, Lusakumunu K, Kapita B, Piot P. Isolation of mycobacteria from HIV seropositive and HIV seronegative patients with and without diarrhoea in Kinshasa, Zaire. Ann Soc Belg Med Trop 1990;70:303-9.

14 Watson J. Tuberculosis in Britain today. BMF 1993;306: 221-2.

15 Daborn CJ, Grange JM. HIV/AIDS and its implication for the control of animal tuberculosis. $\mathrm{Br}$ Vet $\mathcal{F} 1993$; 149 (in press).

16 Dupon M, Ragnaud JM. Tuberculosis in patients with human immunodeficiency virus. 1 . A retrospective multicentre study of 123 cases in France. $Q \mathcal{F}$ Med 1992;85:719-30.

17 Helbert $M$, Robinson D, Buchanan D, Hellyer $T$, McCarthy M, Brown I, et al. Mycobacterial infection in patients infected with the human immunodeficiency virus. Thorax 1990;45:45-8.

18 Centers for Disease Control. Nosocomial transmission of multi-drug resistant tuberculosis among HIV-infected persons-Florida and New York. MMWR 1991;40: persons

19 Frieden TR, Sterling T, Pablos-Mendes A, Kilburn JO, Cauthen GM, Dooley SW. The emergence of drugresistant tuberculosis in New York City. $N$ Engl f Med 1993;328:521-6.

20 Good RC. Opportunistic pathogens in the genus Mycobacterium. Ann Rev Microbiol 1985;39:347-69.

21 Ahn CH, McLarty JW, Ahn SS, Ahn SI. Diagnostic criteria for pulmonary disease caused by Mycobacterium kansasii and Mycobacterium intracellulare. Am Rev Respir Dis 1982;25:388-91.

22 Grange JM, Yates MD. Survey of mycobacteria isolated from urine and the genitourinary tract in south-eas England from 1980 to 1989 . Br f Urol 1992;69:640-6.

23 Levine B, Chaisson RE. Mycobacterium kansasii: a cause of treatable pulmonary disease associated with advanced human immunodeficiency virus (HIV) infection. Ann Intern Med 1991;114:861-8. 